\title{
Estimation of Unreported Catch in a Commercial Trawl Fishery
}

\author{
Margaret Mary McBride \\ U.S. Fish and Wildlife Service, Maryland Fisheries Resources Office \\ 177 Admiral Cochrane Drive, Annapolis, Maryland 21401, U.S.A.
}

and

Åge Fotland

Institute of Marine Research, Box 1870 Nordnes

N-5024 Bergen, Norway

\begin{abstract}
This paper describes a systematic approach that combines research survey and commercial landings data to estimate the total catch of a species, including discards, in a commercial trawl fishery. The method is applied to the 1989 Norwegian bottom trawl fishery for cod (Gadus morhua L.) in the Barents Sea and its utility is evaluated. Bottom trawl survey data together with results from cod-end selectivity studies of the regulated mesh size are used to determine the 'expected' commercial catch composition in percent-at-length, thereby simulating the catch composition of a commercial vessel fishing at randomly located stations. The commercially landed fish numbers-at-length are adjusted upwards to reflect these 'expected' catch levels. The minimum legal market length is then used for a knife-edge estimate of numbers likely to have been discarded.
\end{abstract}

Results indicate a $7.4 \%$ increase in the 'estimated' total catch in 1989 over the numbers landed. Of this increase, 732000 fish or $6.9 \%$ of the total catch would have been discarded or not reported as catch. Results are plausible as examined through comparison of 'estimated' catch mean lengths with mean lengths from: 1) the 1989 Norwegian commercial catch of cod sampled through a surveillance program; 2) 1989 standard Norwegian trawl surveys; and 3) a 1989 cooperative trawl survey in the Barents Sea. Comparisons illustrate basic differences in length selection between survey and commercial trawl gear, and effective differences in mean lengths of catches from randomized surveys and commercially directed fisheries.

Key words: Catch composition, catch simulation, commercial fishery, discards

\section{Introduction}

Total catch, including discard, is a difficult fishery statistic to estimate. Direct observation through a carefully designed sea sampling program onboard commercial vessels is the standard approach. However, such data are expensive to obtain, can be biased, and are generally imprecise relative to landings information. In this paper, the utility of estimates based on data collected through carefully designed scientific surveys of the exploited population, combined with selectivity studies of the appropriate gear, is explored as a practical alternative.

Under certain circumstances, e.g. recruitment of large year-classes as they become vulnerable to commercial gear or the use of relatively small codend mesh sizes by commercial trawlers, a significant component of the catch may be 'undersized', either practically (not marketable for human consumption) or legally; in the latter case they should be thrown back into the sea as discards, in the former case they may be processed for industrial use, i.e. pet foods, plant fertilizers, etc.. In either case, such captures represent a direct loss to a stock's current levels of abundance and biomass. Survival studies of undersized cod onboard a research vessel in the Gulf of Saint Lawrence suggest that after lying on deck for up to 30 minutes typically, at temperatures less than $8^{\circ} \mathrm{C}, 100 \%$ mortality should be assumed (Jean, 1963).

The magnitude discarded of commercially valuable species is a critical concern to effective fishery management, depending on their chances of survival. Stock production may be significantly underestimated if discarding is high and not incorporated into the analysis. For such reasons, a resolution by the International Council for the Exploration of the Sea (ICES, 1976) stressed the importance of collecting discard data, and of reporting these data.

This paper examines a systematic approach to the estimation of total catch. It examines the 1989 
Norwegian commercial bottom trawl fishery for Arcto-Norwegian cod (Gadus morhua L.) in the Barents Sea (ICES Subarea I, Fig. 1). This simulation technique uses standard survey data as a measure of the 'true' exploitable population. Appropriate gear selectivity curves are applied to determine the catch anticipated from using commercial gear. Numbers landed are then adjusted upwards to reflect this 'expected' catch. Lastly, the regulated minimum market length is applied to the 'expected' catch as a cull point, for knife-edge approximation of numbers likely to have been discarded.

\section{Material and Methods}

The effective (regulated) cod-end mesh size for the Norwegian trawl fishery for cod in the Barents Sea (ICES Subarea I) in 1989 (135 mm) was used in conjunction with respective selection curves to determine the 'expected' percent retention at length of the commercial catch, given random fishing during each calendar quarter. Selectivity curves generated using a trouser trawl with the Norwegian trawler M/Tr 'Anny Kræmer' (Alfredo-3 trawl, 137 mm cod-end mesh size) were considered appropriate to represent gear used in the national fishery.

A number of factors will effect mesh selectivity, e.g. catch size, tow duration, tow speed, trawl geometry, the bulbous shape of a cod-end trawl under tow, construction and thickness of mesh twine material, bottom type. The effect of catch size, however, is a factor which cannot be controlled through experimental design. Accordingly, in this study selectivity curves were used that are conditional upon catch size (Isaksen et al., 1989).

Typical catch sizes (mean and mode, total weight in $\mathrm{kg}$ ) of individual hauls in the 1989 Norwegian commercial fishery were evaluated to determine appropriate weight categories for selectivity curves (Isaksen et al., 1989) reflecting patterns in the 1989 national fishery. A selection curve corresponding to an average catch of $1900 \mathrm{~kg} / \mathrm{tow}$ was taken as standard (50\% retention length $\left(L_{50}\right)=54.2$ $\mathrm{cm}$, selection range (s.r.) $=14.2 \mathrm{~cm}$, and selection factor (S.F.) = 3.9) and used in all instances other than the 3rd quarter of the year (Qtr 3), for which a curve corresponding to $450-475 \mathrm{~kg} /$ tow average catch $\left(\mathrm{L}_{50}=56.2 \mathrm{~cm}\right.$, S.r. $=11.8 \mathrm{~cm}$, and S.F. $\left.=4.1\right)$ was determined appropriate for both areas.

The Institute of Marine Research (IMR), Bergen, Norway, has carried out combined bottom trawl and acoustic surveys for cod in the Barents Sea since 1981. Commercial catch statistics were collected routinely for this area through the Norwegian Directorate of Fisheries; IMR collected length and age samples of these landings. Additionally, the Insti- tute of Fishery Technology Research conducted studies of cod-end selectivity for Norwegian bottom trawlers in the Barents Sea during 1989. These data are readily available and represent the most comprehensive information describing the condition of the stock, and the conduct of the Norwegian bottom trawl fishery.

Concerning the effects of gear-induced damage on catch survival, studies of scale loss and mortality indicate that cod are highly resistant to it. No mortality of cod was observed in studies conducted under these conditions at IMR (Soldal et al., MS 1991). The survival rate of cod escaping through a $135 \mathrm{~mm}$ diamond mesh cod-end, typical of the Norwegian bottom trawl fishery, can thus be assumed as $100 \%$.

Estimates of numbers-at-length from IMR standard surveys, conducted using a $35 \mathrm{~mm}$ Campelen 1800 shrimp trawl (Fig. 2), were here assumed to represent the 'true' population composition. It was also assumed that the 1989 winter survey (25 January-15 March 1989) data could be used to estimate population characteristics representative of calendar Qtrs 1 and 2; it was likewise assumed that the autumn survey (9 September-8 October 1989) data would yield estimates representative of Qtrs 3 and 4. To adjust for differences in selectivity between commercial and survey sampling trawl gear, percent retention-at-length from selectivity curves for commercial gear was applied to survey numbersat-length for selected areas and times of year (Table 1). This adjusted survey catch was assumed to represent the 'expected' catch from a commercial vessel fishing the way the survey was conducted, i.e. at random locations.

Relative length frequencies of the 'expected' catch were converted to percentages at length, and applied to actual numbers-at-length of cod landed commercially for the same time and area (Table 1). Thus, reported landings were adjusted upwards to include undersized fish in the exploited population, vulnerable to the gear but not legally marketable. Differences between numbers-at-length 'expected' in the catch and actual numbers landed at length, imply numbers of fish caught but not reported as landings, i.e. discarded or retained for industrial use.

Numbers-at-length landed commercially were adjusted upwards according to the ratio of 'expected' over total numbers landed, and left unchanged where 'expected' catch was lower (Table 1). Granting that no fewer fish can be caught than numbers landed, accommodates this estimation procedure. However, it is recognized that inherent differences in length selection for random vs commercially directed fisheries do exist. Such differences were 


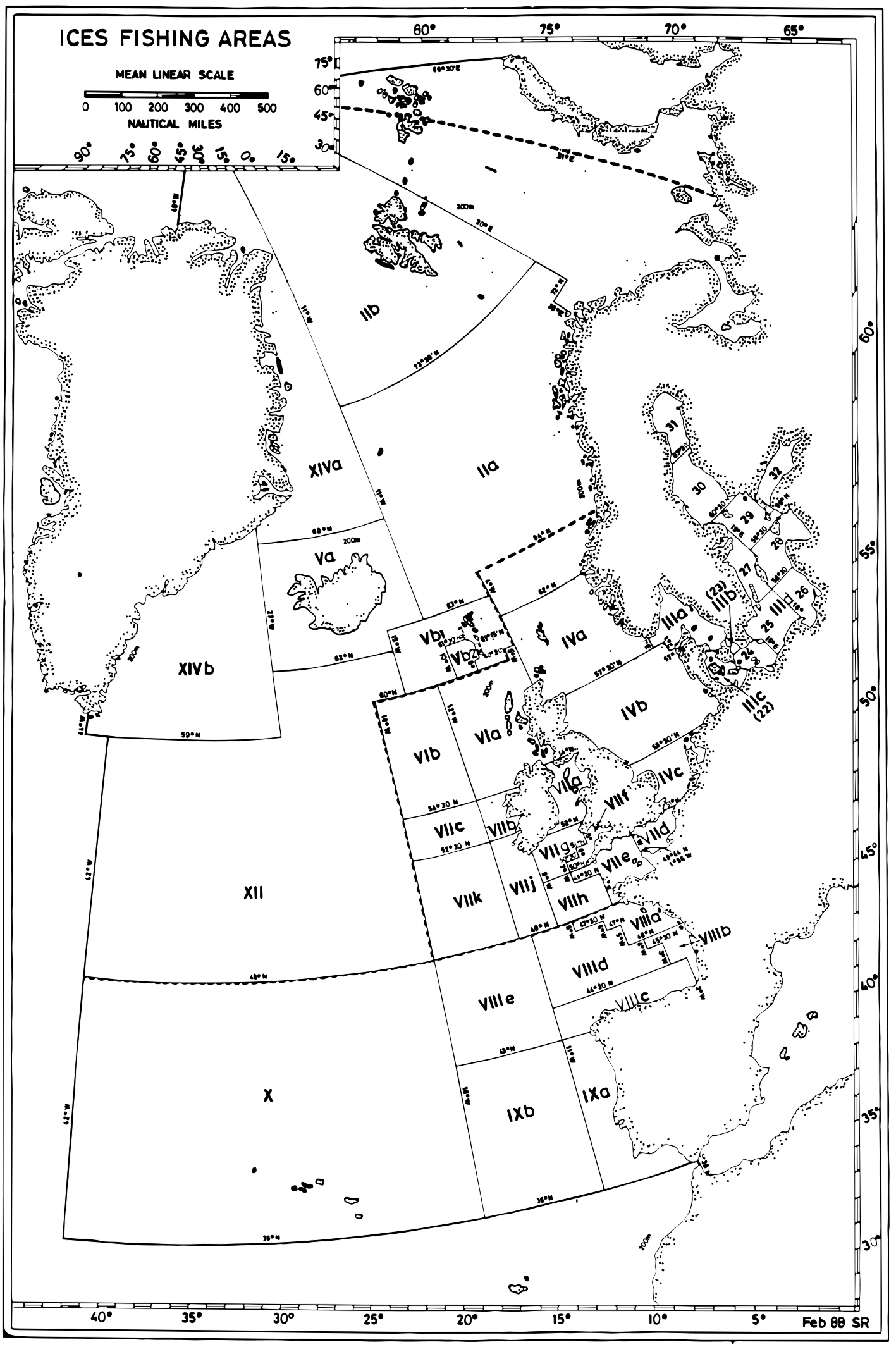

Fig. 1. Map of International Council for the Exploration of the Sea (ICES) Convention Area showing ICES Subareas (Subarea I is the Barents Sea). 


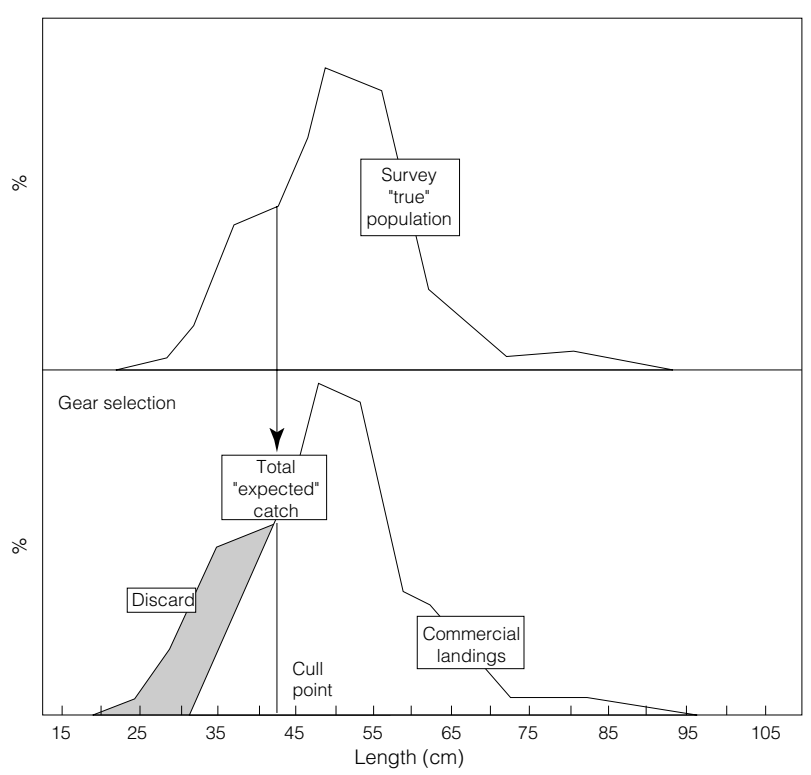

Fig. 2. Schematic representation of discard/total catch estimation technique. Figures on length scale represent lower end of $5-\mathrm{cm}$ intervals.

not simply related to the gear type, but to fishing strategy, particularly the targeting of larger sized fish.

Numbers of smaller (discard sized) cod, 'expected' in the catch but not landed, were included as part of the catch based on percent 'expected' relative to total numbers landed (Table 1). Numbers discarded constitute the 'expected' catch below the regulated minimum market size of $42 \mathrm{~cm}$ set by the Joint Norwegian-Soviet Fishery Commission (Anon., 1988). Numbers landed above this cull point combined with numbers 'expected' in the catch below the cull point were defined as 'estimated' catch. Actual landings data were available only in $5 \mathrm{~cm}$ length intervals, thus the $40-44 \mathrm{~cm}$ interval was used as cull point, regarding fish in this interval (and below) as discard size.

As results are examined, it may be inappropriate to assume independent random samples of individual fish from trawling due to intra-haul correlation, or the tendency of fish to be clustered by size (Pennington and Vølstad, 1994), i.e. the lengths of fish tend to be more similar within tows than between. Standard methods of comparing frequency distributions, e.g. the Kolmogorov-Smirmov test, assume a random sample of individuals and, hence, are not applicable for comparisons of length data from trawl catches.

An alternative method for testing differences in size composition of two populations of interest is to compare the overall mean lengths of trawl catches (Pennington and Vølstad, 1994; Godø et al., 1990). If $m_{j}$ denotes the number of fish caught at the $i^{\text {th }}$ station, and $x_{i j}$ is the measured length of the $j^{\text {th }}$ individual, the mean length of fish within a station is:

$$
\bar{x}_{i}=\Sigma x_{i j} / m_{i}
$$

and the population mean is estimated by the ratio estimator,

$$
\overline{\mathrm{x}}=\Sigma \mathrm{m}_{\mathrm{i}} \overline{\mathrm{x}}_{\mathrm{i}} / \sum \mathrm{m}_{\mathrm{i}}
$$

which is a weighted mean of the station means.

The variance of $\bar{x}$ is estimated by jackknifing (Efron, 1982; Godø et al., 1990). Biases may be introduced into ratio-estimates of mean length and standard error by clustering, or by the variability in catch size between hauls. The 'jackknife nonparametric resampling' method minimizes such effects (Efron, 1982). The differences in mean length of catches from two gear types sampling the same population, at varying times, can also be compared using this approach. Results of this analysis were examined through comparisons of a number of pertinent overall mean lengths (the weighted mean of all means, ignoring empty hauls) and their variances for catches made in ICES Subarea I (Statistical Areas 3 and 13).

Mean lengths of 'estimated' catch were compared with standard survey means within different size ranges by time and area: 1) within the range of exploitation by the gear $\left(x_{i j}>30 \mathrm{~cm}\right)$; 2) within the range of discard sized fish $\left(30 \leq x_{i j} \leq 44 \mathrm{~cm}\right)$; and 3 ) above the length of $100 \%$ retention $\left(x_{i j}>74\right.$ $\mathrm{cm})$. Furthermore, 'estimated' and 'expected' catch means $\left(x_{i j}>30 \mathrm{~cm}\right)$ were compared to suggest the utility of this simulation method for the full range of exploitable lengths.

Mean lengths of 'estimated' catch were also compared with commercial catch mean lengths from the 1989 Norwegian cod trawl fishery obtained through Norway's Surveillance Program. Initiated in 1983, this program functioned to monitor levels of stock removal for compliance with the '15 Percent Rule' through direct observation, as this rule was defined such that, an area is subject to closure if more than 15 percent of the catch-per-tow within an area falls below the length of $25 \%$ retention with respect to the selectivity curve adopted for the legal cod-end mesh size (135 mm in 1989).

Similar comparisons are made with mean lengths from the 1989 Cooperative Trawl Survey (COOP Survey) in the Barents Sea (Godø and Korsbrekke, MS 1990). This survey (24-29 October 1989) was carried out by 15 trawlers using standard commercial gear (typically Alfredo-3 or 
TABLE 1. An example of estimation technique (landings adjusted upwards) for Norwegian total catch-at-length of Barents Sea cod, as applied to 1989 Quarter 1 landings fromICES Subarea I, Statistical Area 3 (see Fig. 1).

\begin{tabular}{|c|c|c|c|c|c|c|c|c|}
\hline $\begin{array}{l}\text { Fish } \\
\text { Length } \\
(\mathrm{cm})\end{array}$ & $\begin{array}{l}\text { Winter } \\
\text { Survey } \\
\text { Number } \\
\text { Landed }\end{array}$ & $\begin{array}{c}\% \\
\text { Retained } \\
\text { for } 1900 \\
\mathrm{~kg} / \mathrm{tow}\end{array}$ & $\begin{array}{l}\text { Number } \\
\text { Expected }\end{array}$ & $\begin{array}{c}\% \\
\text { Expected }\end{array}$ & $\begin{array}{l}\text { QTR } 1 \\
\text { Number } \\
\text { Landed }\end{array}$ & $\begin{array}{c}\% \\
\text { Landed }\end{array}$ & $\begin{array}{c}\% \\
\text { Change }\end{array}$ & $\begin{array}{c}\text { QTR 1 } \\
\text { Total } \\
\text { Expected } \\
\text { Catch }\end{array}$ \\
\hline \multicolumn{9}{|l|}{$0-4$} \\
\hline $5-9$ & 183 & & & & & & & \\
\hline $10-14$ & 5800 & & & & & & & \\
\hline $15-19$ & 484 & & & & & & & \\
\hline $20-24$ & 3034 & & & & & & & \\
\hline $25-29$ & 7854 & & & & & & & \\
\hline $30-34$ & 19631 & 0.010 & 196 & 0.006 & & & 0.006 & 20434 \\
\hline $35-39$ & 36505 & 0.031 & 1132 & 0.036 & & & 0.036 & 117792 \\
\hline $40-44$ & 31054 & 0.116 & 3602 & 0.115 & 6900 & 0.002 & 0.113 & 374953 \\
\hline $45-49$ & 17754 & 0.260 & 4616 & 0.147 & 153500 & 0.047 & 0.100 & 480475 \\
\hline $50-54$ & 14818 & 0.423 & 6268 & 0.200 & 628300 & 0.192 & 0.007 & 652426 \\
\hline $55-59$ & 11483 & 0.610 & 7005 & 0.223 & 1207800 & 0.370 & -0.147 & 1207800 \\
\hline $60-64$ & 6338 & 0.780 & 4944 & 0.158 & 788900 & 0.241 & -0.084 & 788900 \\
\hline $65-69$ & 2016 & 0.929 & 1873 & 0.060 & 216400 & 0.066 & -0.007 & 216400 \\
\hline $70-74$ & 788 & 0.988 & 779 & 0.025 & 118600 & 0.036 & -0.011 & 118600 \\
\hline $75-79$ & 363 & 1.000 & 363 & 0.012 & 41800 & 0.013 & -0.001 & 41800 \\
\hline $80-84$ & 326 & 1.000 & 326 & 0.010 & 34900 & 0.011 & -0.000 & 34900 \\
\hline $85-89$ & 134 & 1.000 & 134 & 0.004 & 34900 & 0.011 & -0.006 & 34900 \\
\hline $90-94$ & 11 & 1.000 & 11 & 0.000 & 20900 & 0.006 & -0.006 & 20900 \\
\hline $95-99$ & 79 & 1.000 & 79 & 0.003 & 6900 & 0.002 & 0.000 & 8223 \\
\hline $100-104$ & 57 & 1.000 & 57 & 0.002 & & & 0.002 & 5933 \\
\hline $105-109$ & & & & & 6900 & 0.002 & -0.002 & 6900 \\
\hline$>30 \mathrm{~cm}$ & 141357 & & & & & & & \\
\hline Total & 158712 & & $\begin{array}{l}31384 \\
22.20 \% 1\end{array}$ & 1.000 & 3266700 & 1.000 & & $\begin{array}{l}4131336 \\
+26.47 \%{ }^{2}\end{array}$ \\
\hline
\end{tabular}

1 refers to percentage expected (retained) in catch from true survey population.

2 refers to percent increases in total expected catch over landings.

Cortesi-3 trawls) with legal cod-end mesh size (135 $\mathrm{mm})$. Two vessels using the standard survey Campelen 1800 shrimp trawl conducted 'parallel' hauls alongside those trawlers that used standard commercial gear. Three hauls every 24 hours additional to those allocated through the systematic design of the survey, were selected by the fishermen as would be done commercially, i.e. on concentrations of larger fish to maximize profit.

Mean lengths were compared in different categories assuming that: 1) 'estimated' catch should resemble commercial catch as sampled through the Surveillance Program, and the COOP Survey catch from stations selected by fishermen; and that 2) standard Norwegian survey and COOP Survey parallel hauls should be similar, as they both were conducted using standard survey gear.

The mean lengths of catch estimates presented were regarded as fixed. In reality, mean lengths of commercial landings and catch were determined from landings samples, thus, available data did not facilitate estimation of their standard error.

\section{Results}

\section{Total Catch Estimates}

'Estimated' numbers of cod caught in ICES Subarea I in the Norwegian bottom trawl fishery during 1989 are presented in Table 2. This value represents actual landings of fish above the cull point, plus the 'expected' catch within the discard range (Fig. 3 and 4). 'Estimated' numbers caught total 10.7 million, a $7.4 \%$ increase over the numbers landed. Of this increase, 732000 fish were discarded or not reported, representing $6.9 \%$ of the 'estimated' total catch based on the regulated cull point.

\section{Comparisons of Mean Length}

1) Comparisons of Norwegian 'estimated' catch mean lengths, by quarter and area, with standard survey mean lengths within the exploitable 
TABLE 2. The 1989 Norwegian Barents Sea cod trawl fishery estimates of numbers landed, numbers 'expected' in catch, numbers 'estimated' in catch, and numbers discarded (knife-edged) in ICES Subarea I.

\begin{tabular}{|c|c|c|c|c|c|c|c|c|c|c|c|c|}
\hline \multirow[b]{2}{*}{$\begin{array}{c}\text { Fish } \\
\text { longth } \\
(\mathrm{cm})\end{array}$} & \multirow[b]{2}{*}{$\begin{array}{l}\text { Number } \\
\text { Landed }\end{array}$} & \multicolumn{2}{|c|}{ Quarters 1 and 2} & \multirow[b]{2}{*}{$\begin{array}{c}\text { Number } \\
\text { Discarded }\end{array}$} & \multirow[b]{2}{*}{$\begin{array}{l}\text { Number } \\
\text { Landed }\end{array}$} & \multicolumn{2}{|c|}{ Quarters 3 and 4} & \multirow[b]{2}{*}{$\begin{array}{c}\text { Number } \\
\text { Discarded }\end{array}$} & \multirow[b]{2}{*}{$\begin{array}{l}\text { Length } \\
\text { Landed }\end{array}$} & \multicolumn{2}{|c|}{ Total } & \multirow[b]{2}{*}{$\begin{array}{c}\text { Number } \\
\text { Discarded }\end{array}$} \\
\hline & & $\begin{array}{l}\text { Expected } \\
\text { Number } \\
\text { in Catch }\end{array}$ & $\begin{array}{l}\text { Estimated } \\
\text { Number } \\
\text { in catch }\end{array}$ & & & $\begin{array}{l}\text { Expected } \\
\text { Number } \\
\text { in Catch }\end{array}$ & $\begin{array}{l}\text { Estimated } \\
\text { Number } \\
\text { in Catch }\end{array}$ & & & $\begin{array}{l}\text { Expected } \\
\text { Number } \\
\text { in Catch }\end{array}$ & $\begin{array}{l}\text { Estımated } \\
\text { Number } \\
\text { in Catch }\end{array}$ & \\
\hline $\begin{array}{r}30-34 \\
35-39 \\
40-44 \\
45-49 \\
50-54 \\
55-59 \\
60-64 \\
65-69 \\
70-74 \\
75-79 \\
80-84 \\
85-89 \\
90-94 \\
95-99 \\
100-104 \\
105-109 \\
110-114 \\
115-119 \\
120-124 \\
125-129\end{array}$ & $\begin{array}{r}164561 \\
470100 \\
1043800 \\
1486900 \\
1016800 \\
376000 \\
135400 \\
57800 \\
35200 \\
50900 \\
21000 \\
6961 \\
6961\end{array}$ & $\begin{array}{r}30611 \\
176860 \\
563428 \\
801473 \\
1068299 \\
1568707 \\
1043705 \\
376000 \\
158615 \\
60346 \\
51816 \\
50900 \\
21538 \\
12268 \\
8837 \\
6961\end{array}$ & $\begin{array}{r}30611 \\
176860 \\
563428 \\
470100 \\
1043800 \\
1486900 \\
1016800 \\
376000 \\
135400 \\
57800 \\
35200 \\
50900 \\
21000 \\
6961 \\
6961\end{array}$ & $\begin{array}{r}30611 \\
176860 \\
398867\end{array}$ & $\begin{array}{r}3100 \\
3100 \\
16100 \\
73100 \\
256100 \\
655100 \\
1173700 \\
1391600 \\
929600 \\
316800 \\
118700 \\
37300 \\
34500 \\
15500 \\
12600 \\
3100 \\
3100\end{array}$ & $\begin{array}{r}6853 \\
21424 \\
119492 \\
271155 \\
586842 \\
706019 \\
1173700 \\
1462133 \\
1022019 \\
368842 \\
124430 \\
55184 \\
35273 \\
15500 \\
43232 \\
8190 \\
3100\end{array}$ & $\begin{array}{r}6853 \\
21424 \\
119492 \\
73100 \\
256100 \\
655100 \\
1173700 \\
1391600 \\
929600 \\
316800 \\
118700 \\
37300 \\
34500 \\
15500 \\
12600 \\
3100 \\
3100\end{array}$ & $\begin{array}{r}3753 \\
18324 \\
103392\end{array}$ & $\begin{array}{r}3100 \\
3100 \\
180661 \\
543200 \\
1299900 \\
2142000 \\
2190500 \\
1767600 \\
1065000 \\
374600 \\
153900 \\
88200 \\
55500 \\
22461 \\
12600 \\
10061 \\
3100\end{array}$ & $\begin{array}{r}37464 \\
198284 \\
682920 \\
1072628 \\
1655141 \\
2274726 \\
2217405 \\
1838133 \\
1180634 \\
429188 \\
176246 \\
106084 \\
56811 \\
27768 \\
52069 \\
15151 \\
3100\end{array}$ & $\begin{array}{r}37464 \\
198284 \\
682920 \\
543200 \\
1299900 \\
2142000 \\
2190500 \\
1767600 \\
1065000 \\
374600 \\
153900 \\
88200 \\
55500 \\
22461 \\
12600 \\
10061 \\
3100\end{array}$ & $\begin{array}{r}34364 \\
195184 \\
502259\end{array}$ \\
\hline $\begin{array}{c}\text { Total } \\
\%\end{array}$ & 4872383 & $\begin{array}{r}6000364 \\
+21.15 \%\end{array}$ & $\begin{array}{r}5478721 \\
+12.44 \%\end{array}$ & $\begin{array}{r}606338 \\
11.07 \%\end{array}$ & 5049300 & $\begin{array}{r}6029588 \\
+19.41 \%\end{array}$ & $\begin{array}{r}5174769 \\
+2.48 \%\end{array}$ & $\begin{array}{r}125469 \\
2.42 \%\end{array}$ & 9921683 & $\begin{array}{r}12029952 \\
+21.25 \%\end{array}$ & $\begin{array}{r}10653490 \\
+7.38 \%\end{array}$ & $\begin{array}{r}731807 \\
6.87 \%\end{array}$ \\
\hline
\end{tabular}

Discard cull point is based on the regulated mınimum market size through Joint Norwegian-Sovlet Fishery Commission.

Total Estimated Catch $=$ Landings ( $>44 \mathrm{~cm}$ ) + Expected Catch $(\$ 44 \mathrm{~cm}$ ).
Bottom line (\%): Percentage increase over numbers landed, Percentage increase over numbers landed, and percentage discarded of estımated total catch.

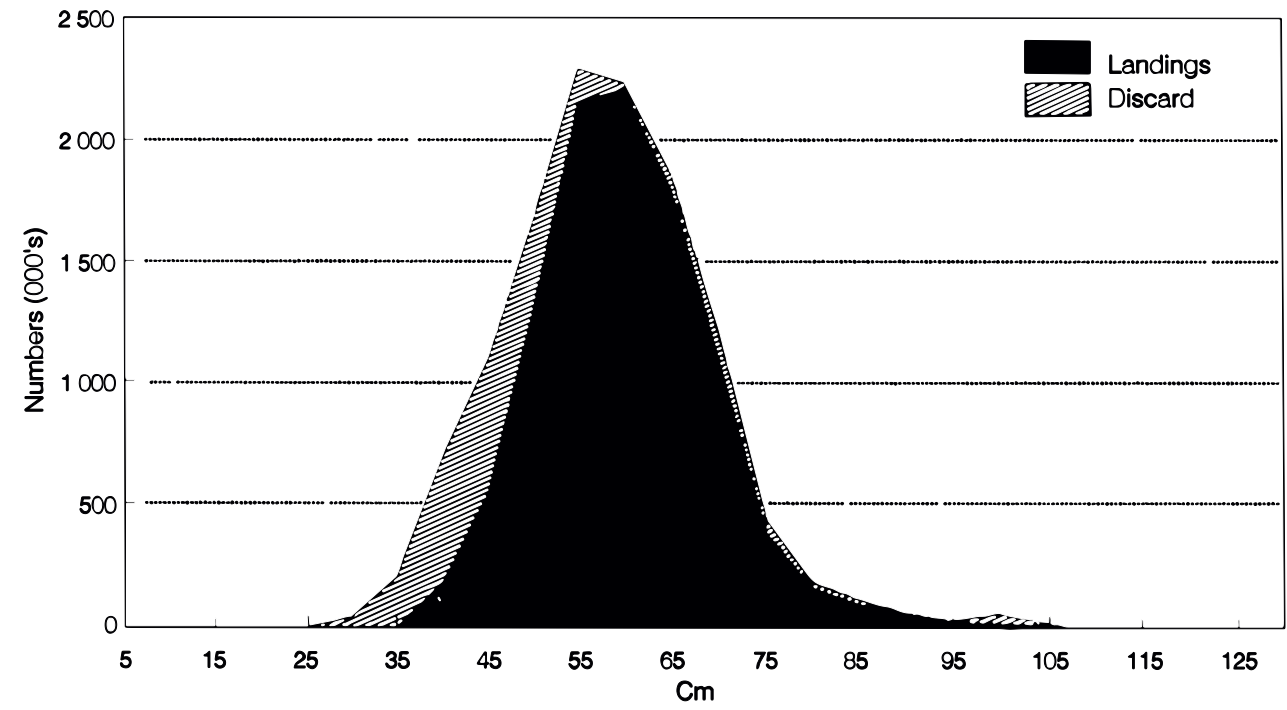

Fig. 3. Norwegian landings and 'expected' total catch estimates for 1989 Barents Sea ArctoNorwegian Cod within the exploitable length range $(>30 \mathrm{~cm})$. Figures on length scale represent lower end of 5-cm intervals.

length range $(>30 \mathrm{~cm})$ on average showed larger fish $(5-15 \mathrm{~cm})$ in the commercial catch (Table 3). This followed the tendency that commercial fishermen do not fish randomly, but rather aim to maximize profit by targeting the most marketable, i.e. most valuable sized fish.
2) The tendency in Comparison 1 was again observed through comparison of mean lengths $(>30 \mathrm{~cm})$ from COOP Survey parallel hauls using standard survey trawl gear, with hauls made in locations selected by commercial fishermen to maximize catch. In this comparison, as an- 


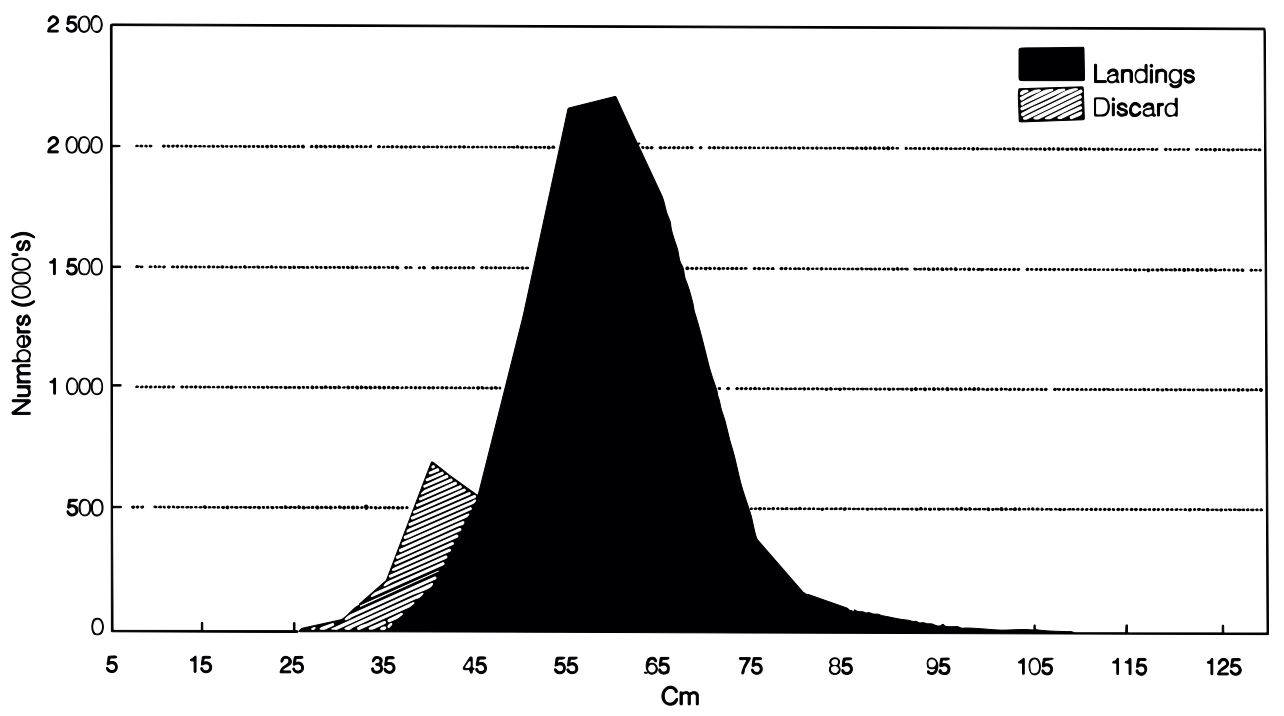

Fig. 4. Norwegian landings and discard comprising the 'estimated' catch for 1989 Barents Sea Arcto-Norwegian Cod based on the 40-44 cm cull point. Figures on length scale represent lower end of 5-cm intervals.

ticipated, mean lengths from parallel hauls were not statistically different from the standard survey means. Stations selected by fishermen showed larger fish (about $10 \mathrm{~cm}$ ) than the comparable catch from the systematic survey.

3) Similar results were observed in an analogous comparison of means: standard survey means compared with COOP Survey means from stations selected by commercial fishermen. Here, the standard survey means were again not statistically different from COOP Survey means from parallel hauls, and COOP Survey stations selected by fishermen were comparable to 'estimated' catch means. As observed in Comparisons 1 and 2, mean lengths from COOP Survey stations selected by fishermen were larger (about $10 \mathrm{~cm}$ ) than survey means. By category, mean lengths in Comparisons 1, 2, and 3 were not statistically different.

4) Mean lengths from the standard survey were then compared with COOP Survey means from parallel hauls. These catches from parallel hauls were assumed comparable because both were made with standard survey gear using random or systematic location of stations. Mean lengths from the two surveys were not statistically different as measured through their standard errors.

5) Mean lengths from COOP Survey stations selected by fishermen were compared with means of 'estimated' catch. As anticipated, mean lengths from these two sources were very similar, particularly during Qtr 4 when the COOP Survey actually took place.

6) Commercial catch mean lengths sampled by the Surveillance Program, available for Qtrs 1 and 2 only, were not statistically different from 'estimated' catch means.

7) 'Estimated' catch means were very similar to 'expected' catch means, suggesting that overall length composition of commercial catch $(>30 \mathrm{~cm}$ ) was simulated reasonably using this approach. This was supported by COOP Survey stations selected by fishermen, which had similar catch means to both 'estimated' and 'expected'.

\section{Comparisons of Mean Length for Discard Sized Fish}

1) Mean lengths of 'estimated' catch below the minimum market size, and standard survey means in this range $(30-44 \mathrm{~cm})$, are compared (Table 4). These means were similar, however survey means were slightly smaller $(2-4 \mathrm{~cm})$ due to differences in selectivity between commercial and survey gear. Mean lengths of commercial catches were larger due to use of cod-end mesh sizes allowing escapement of smaller fish.

2) Similar to Comparison 1, mean lengths of discard sized fish from COOP Survey parallel hauls and COOP Survey stations selected by fishermen were very similar, showing slightly larger means for catch taken using commercial gear in a directed effort. 
TABLE 3. Comparison of cod mean lengths $\bar{X}$ ) with standard error (S.E. $)^{1}$ for 1989 exploitable catch $(>30 \mathrm{~cm})$ from standard Norwegian winter (Qtrs 1 and 2) and autumn (Qtrs 3 and 4) surveys, the Cooperative Survey, estimated total catch, the Surveillance Program, and expected total catch for ICES Subarea I statistical areas 3 and 13 by calendar quarter.

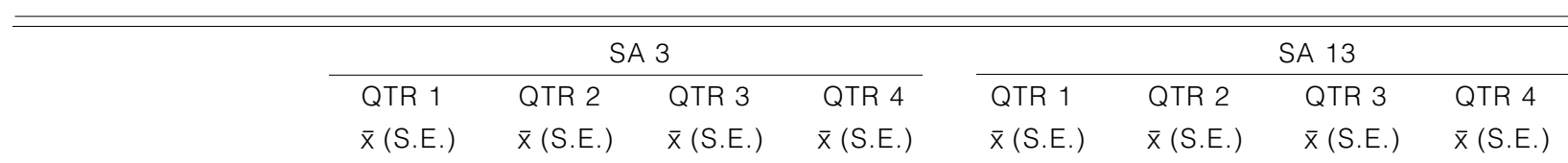

1) Standard Survey vs

Estimated Total ${ }^{2}$

Catch

2) COOP Parallel ${ }^{3}$

Hauls

vs

COOP Stations

Selected by

Fishermen

3) Standard Survey

vs

COOP Stations

Selected by

Fishermen

4) Standard Survey

vs

COOP Parallel

Hauls

5) Coop Stations

Selected by

Fishermen

vs

Estimated Total

Catch

6) Surveillance

Program

vs

Estimated Total

Catch

\author{
$48.4(3.6) \quad 48.4(3.6) \quad 57.2(1.9) \quad 57.2(1.9)$ \\ $57.2(-) \quad 54.1(-) \quad 63.4(-) \quad 66.7(-)$ \\ $57.2(-), 54.1(-) \quad 63.4(-)+66.7(-)$
}

$42.4(1.0) \quad 42.4(1.0)$

$56.3(1.6) \quad 56.3(1.6)$

$56.0(-) \quad 53.3(-) \quad 63.2(-) \quad 66.6(-)$

$56.7(2.6)$

$55.8(1.0)$

$66.9(0.8)$

$64.5(0.5)$

$57.2(1.9)$

$56.3(1.6)$

$66.9(0.8)$

$64.5(0.5)$

$57.2(1.9)$

$56.3(1.6)$

$56.7(2.6)$

$55.8(1.0)$

$66.9(0.8) \quad 66.9(0.8)$

$64.5(0.5) \quad 64.5(0.5)$

$63.4(-) 66.7(-)$

$63.2(-) 66.6(-)$

$54.8(4.7) \quad 56.8(4.3)$

$48.9(2.9) \quad 56.7(6.1)$

$57.2(-) \quad 54.1(-)$

$56.0(-) 53.3(-)$

7) Expected Total ${ }^{4}$

Catch

vs

$56.5(-) \quad 55.1(-) 65.0(-) \quad 65.8(-)$

$55.3(-) \quad 54.0(-) \quad 63.3(-) \quad 64.3(-)$

Estimated Total

$57.2(-) \quad 54.1(-) \quad 63.4(-) 66.7(-)$

$56.0(-) \quad 53.3(-) \quad 63.2(-) 66.6(-)$

Jackknife estimates of mean and standard error (see Efron, 1982).

2 Estimated Total Catch $=$ Landings $>$ cull point + Expected Total Catch $<$ cull point.

3 Cooperative survey conducted October 24-29, 1989.

4 Estimated, and Expected Total catch means are arithmetic and fixed, estimates of standard error are unavailable.

3) As observed for the full range of exploitable lengths $(>30 \mathrm{~cm})$, comparisons of means in the discard range $(30-44 \mathrm{~cm})$ of 'estimated' catch with COOP Survey stations selected by fishermen were very similar. As would be anticipated, the directed effort showed slightly larger means. 
TABLE 4. Comparison of cod mean lengths $(\bar{X})$ during 1989 with standard error (S.E.) ${ }^{1}$ for discard sized fish (30-44 $\mathrm{cm}$ ), and lengths above 100\% selection (>74 cm) from Norwegian winter (Qtrs $1 \& 2$ ) and autumn (Qtrs $3 \& 4$ ) standard surveys, the Cooperative Survey, the Surveillance Program, estimated and expected total catch for ICES Subarea I statistical areas 3 and 13 by calendar quarter.

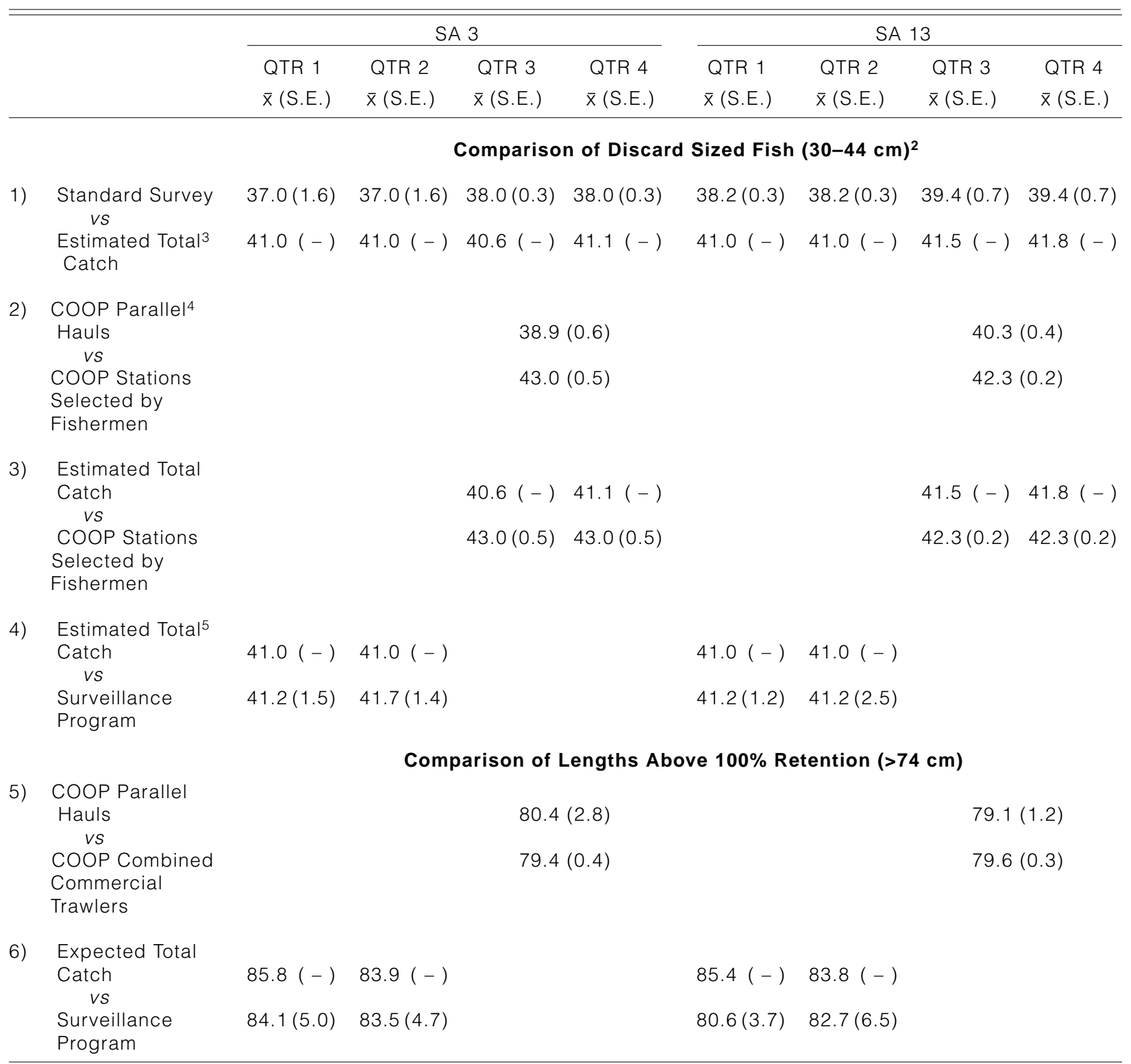

1 Jackknife method used for estimates of mean and standard error (see Efron, 1982).

2 Discard cull point $(40-44 \mathrm{~cm})$ based on regulated minimum market size through Joint Norwegian-Soviet Fishery Commission.

3 Estimated Total Catch $=$ Landings $>$ cull point + Expected Total Catch < cull point.

4 Cooperative survey conducted 24-29 October 1989.

5 Estimated, and Expected Total catch means are arithmetic and fixed, estimates of standard error are unavailable.

4) Commercial catch mean lengths for discard sized fish sampled directly by observers through the Surveillance Program were not statistically different from 'estimated' catch means in this size range.
Comparison of Mean Lengths Above $100 \%$ Retention

5) Means above the length of $100 \%$ retention on the selectivity curve were not statistically different for COOP Survey parallel hauls and 
COOP Survey combined commercial trawlers (Table 4). Thus, lengths from commercial and survey gear collected using a single systematic survey design are shown to compare well outside the influence of cod-end selection.

\section{Discussion and Conclusion}

The method presented for the estimation of total catch (including discards) in a commercial bottom trawl fishery is introduced as a practical alternative (where data are available and suitable) to making direct observation onboard commercial vessels.

As presented, this method is most applicable to demersal species for which survey sampling is meaningful, and might well be adapted to other fisheries. It makes three basic assumptions: 1) that survey results (relative numbers at length) are representative of the exploitable population; 2) the exploited population is not effectively segregated by size with respect to the length composition of commercial catch; and 3 ) that relative proportions of commercially undersized fish in the catch can be estimated reasonably by applying the selectivity of the effective commercial gear to survey estimates of the exploited population composition. Estimates of the mean length of total catch made through this method for market sized, and undersized fish, were not statistically different from the mean lengths of commercial catch observed directly through the Surveillance Program.

Regarding the first assumption, fish tend to be caught in clusters during marine trawl surveys. It has been demonstrated that assuming individual survey measurements to form random samples of a population may not be valid due to intra-haul correlation (Pennington and Vølstad, 1994). Resulting estimates of population composition at length may be highly variable.

Under assumption 2, the question arises from comparisons of mean length as to whether commercial fishermen target larger fish to the point of excluding undersized fish from the catch. Comparison of discard sized fish from COOP Survey parallel hauls with fish caught using commercial gear at stations selected by fishermen, suggest that this is not the case (Table 4). Mean lengths within this range are similar for COOP Survey parallel hauls, the 'estimated' catch, and COOP Survey stations selected by fishermen in a directed effort, despite differences in gear selectivity. Moreover, management concerns regarding high levels of discarding persist, even as current fishery technology offers increased sophistication towards making such a directed effort.
Concern arises with assumption 3, because fishermen do not fish randomly, but rather tend to maximize catch of the larger fish. This explains instances in the estimation procedure where the percent 'expected' catch is less than the percent landed at a particular length interval. Such instances are more likely to be observed at larger length intervals, where the fish landed have been targeted by commercial fishermen. This being so, the knife-edge approximations of numbers within the range likely to have been discarded introduce no major concern.

Generally, for the full range of exploitable fish, higher numbers were 'expected' in the catch than were landed (Table 2 and Fig. 2). For larger sized fish, this may be due to the assumption in the estimation procedure that no less fish can be caught than landed. Thus, numbers 'expected' in the catch never fall below the reported numbers landed. Fishermen may, in effect, avoid undersized fish as readily as they target larger fish. Thereby, estimates of discards, based on randomized measures of population composition, may be overestimates. The magnitude of this bias may vary from year to year, relative to year-class strength.

Additional studies of catch length composition relative to fishing strategy are needed to quantify this source of potential bias. Of similar importance, quantifying the bias which results from not including discard in estimates of stock production needs further study. The magnitude of such biases will vary relative to the species, population length composition and fishing practices. In this example, however, the differences observed between actual numbers landed and numbers 'expected' in the legal size range are similar (Fig. 2).

Comparisons of mean length showed clear trends and differences in commercial and survey catch from the same population. Mean lengths of exploitable catch $(>30 \mathrm{~cm})$ from commercial trawls tended to be larger $(5-15 \mathrm{~cm})$ than those of catch from survey gear. This tendency is consistent with the understanding that fishermen do not fish randomly, but target larger fish to maximize profit. However, comparisons of mean lengths for 'estimated' catch and COOP Survey catch from stations selected by fishermen showed little difference for comparable time and area, and 'estimated' catch means were not statistically different from commercial catch means sampled through the Surveillance Program. 'Estimated' catch means compared with 'expected' catch means are very similar, suggesting that length composition of the overall commercial catch (landings plus discard) can be simulated reasonably using the proposed systematic approach. 
This is supported by COOP Survey (Qtr 4) mean lengths from stations selected by fishermen, which were not statistically different from either the 'estimated' or the 'expected' catch means.

Comparison of mean lengths of discard sized fish from survey and 'estimated' commercial catch tends toward slightly lower means from survey catch, due to differences in selectivity between the two gear types. Regulated commercial cod-end mesh sizes allow escapement in this size range; thereby, mean lengths are slightly increased. Selection by the gear appears to minimize this difference; mean lengths of the 'estimated' catch and the COOP Survey stations selected by fishermen were very similar in this range. Whereas, comparisons of 'estimated' catch and commercial catch mean length as sampled through the Surveillance Program were not statistically different. This suggests the method's utility in simulating the commercial catch of discard sized fish.

Means lengths of fish above the length of $100 \%$ retention on the selectivity curve were not statistically different between COOP Survey parallel hauls and COOP Survey combined commercial trawlers. Here data collected using either commercial or survey gear, and the same systematic survey sampling design were compared at lengths outside the influence of cod-end selectivity. Results suggest that survey and commercial measures of a unique population are comparable given appropriate assumptions regarding gear selectivity. The conduct of the fishery as related to changes in regulated cod-end mesh size, exploitation pattern, and year-class strength should also be considered in the analytical design and the interpretation of results.

Discards estimated in this analysis were conservative relative to peak rates estimated during 1953-54 (40\% by number and 20\% by weight), 1957 and 1958 (Garrod, 1967). This would be anticipated due to increasing awareness of excessive discarding as a management problem, and more effective regulation of the fishery.

Garrod's method used estimated actual abundance of partially recruited age groups, corrected for their availability to the trawl fleet. Values were compared with catch-per-unit effort recorded by English trawlers; differences were used to reconstruct trends in discard rates by particular age groups. He suggests that his estimates are probably low due to original assumptions of the method.
The method described in this paper is direct, systematic, and based on the most reliable data available on condition of the stock and conduct of the fishery. Results are plausible as examined through comparison of 'estimated' catch mean lengths with those from independent sources of commercial catch composition data for this fishery, i.e. direct observations of the 1989 fishery through the Surveillance Program, and the 1989 COOP Survey in the Barents Sea.

\section{Acknowledgements}

Appreciation is expressed to Tore Jakobsen, Michael Fogarty, and Richard McGarvey for their critiques of this manuscript. Discussions with Arvid Hylen, Jon Helge Vølstad, Michael Pennington, Olav Rune Godø and Knut Sunnanå gave useful insights into the analytical design and the interpretation of results.

\section{References}

ANON. 1988. Joint Norwegian-Soviet Fishery Commission. Protocol: $17^{\text {th }}$ Session. Oslo, Norway 12-16 December 1988. $16 \mathrm{p}$.

EFRON, B. 1982. The jackknife, the bootstrap and other resampling plans. CBMS NSD Regional Conference Series in Applied Mathematics. No. 38. Society for Industrial and Applied Mathematics. Philadelphia. 93 $\mathrm{p}$.

GARROD, D. J. 1967. Population dynamics of the ArctoNorwegian cod. J. Fish. Res. Board Canada, 24(1): 45-190.

GOD $\varnothing$, O. R., and K. KORSBREKKE. MS 1990. Comparison of catches of cod from Norwegian commercial trawlers and research vessels. ICES C. M. Doc., No. $\mathrm{G}: 54$.

GOD $\varnothing$, O. R., M. PENNINGTON, and J. H. VØLSTAD. 1990. Effect of tow duration on length composition of trawl catches. Fish. Res., 9: 165-179.

ICES. 1976. Resolutions passed at the $63^{\text {rd }}$ Statutory Meeting, 1975. ICES Proc.-Verb. Reun., 1975: 152.

ISAKSEN, B., S. LISOVSKY, and V. A. SAKHNO. 1989. A comparison of the selectivity in codends used by the Soviet and Norwegian trawler fleet in the Barents Sea. Institute of Fishery Technology Research, Bergen. Oppdragsrapport No. 3/1989, 31 p.

JEAN, Y. 1963. Discards of fish at sea by northern New Brunswick draggers. J. Fish. Res. Board Can., 20(2): 497-524.

PENNINGTON, M., and J. H. VØLSTAD. 1994. Assessing the effect of intra-haul correlation and variable density on estimates of population characteristics from marine surveys. Biometrics, 50: 725-732.

SOLDAL, A. V., B. ISAKSEN, J. E. MARTELINSSON, and A. ENGÅS. MS 1991. Scale damage and survival of cod and haddock escaping from a demersal trawl. ICES C.M. Doc., No. B:44. 
